\title{
The association between cell assemblies and transient dynamics
}

\author{
Christian Tetzlaff ${ }^{1,2^{*}}$, Sakyasingha Dasgupta ${ }^{1,2}$, Florentin Wörgötter $^{1,2}$ \\ From The Twenty Third Annual Computational Neuroscience Meeting: CNS*2014 \\ Québec City, Canada. 26-31 July 2014
}

Neural systems show a wide variety of complex dynamics on different time scales. Specifically, on the short time scale of neuronal activations (milliseconds to seconds), several theoretical models (e.g., state-dependent networks or liquid state machines [1]) demonstrate that complex (transient) dynamics enables neural circuits to process a broad range of nonlinear problems. In other words, neural circuits process inputs to transform them into desired outputs. This approach, amongst others, is based on the inherent stochasticity (randomness) of neural systems. On the other hand, the slower mechanisms of synaptic plasticity (minutes to hours) adapt synaptic efficacies to form ordered structures as neural cell assemblies [2]. Each cell assembly consists of a group of strongly interconnected neurons and its dynamics serves as an associative memory of the previously experienced input. This type of dynamics is in stark contrast to the needed randomness of connectivity for transient dynamics. Intriguingly, several experiments show that both concepts coexist in the same neural circuits [3,4].

In this study we analyze how this coexistence of transient dynamics and cell assemblies can emerge in one neural circuit. The neural network, we investigate, consists of rate- based neurons with connections adapted by a generic combination of Hebbian plasticity and synaptic scaling [5]. A subset of neurons receives repeatedly a time-varying input and forms a cell assembly (Figure 1). Further repetitions of the input lead to a gradual growth of the cell assembly by incorporating more neurons. In parallel, the network is required to compute a desired nonlinear version of the input. To test whether this computation is successful, the connections between the neurons of the network and a linear output neuron are adapted by a

\footnotetext{
* Correspondence: tetzlaff@phys.uni-goettingen.de

${ }^{1}$ III. Institute for Physics - Biophysics, Georg-August University, Göttingen, Germany

Full list of author information is available at the end of the article
}

supervised learning algorithm [6]. Remarkably, the performance of the computation increases with the growth in size of the cell assembly. Thus, the slow, ordering dynamics of synaptic plasticity supports the computational capability of the fast transient dynamics. Furthermore, as the cell assemblies are topologically compact, the network is able to perform several computations in parallel (green and red cell assemblies in Figure 1). However, if the cell assemblies become neighbors, dependent on the input, one cell assembly can capture neurons from the other assembly (stripped area in Figure 1). Thus, the cell assemblies compete for computational resources, namely neurons and synapses. Therefore, our work shows a new functional role of cell assemblies in neuronal systems, whereby both stable and transient dynamics are byproduct of the same neural circuit. Thus, both concepts are not mutually exclusive but that they interact with each other in a positive way.

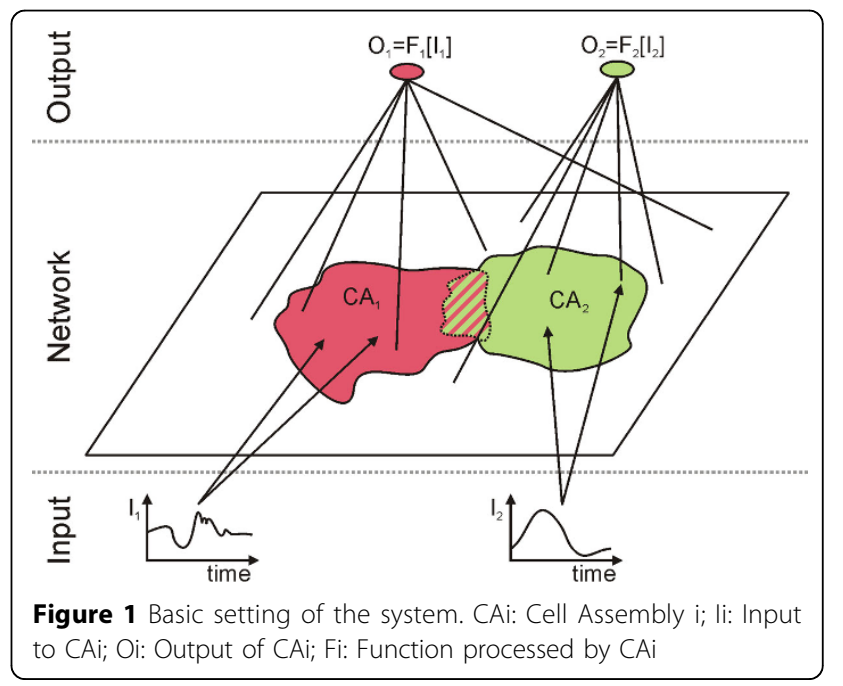




\section{Authors' details}

'III. Institute for Physics - Biophysics, Georg-August University, Göttingen, Germany. ${ }^{2}$ Bernstein Center for Computational Neuroscience, Göttingen, Germany.

Published: 21 July 2014

\section{References}

1. Buonomano DV, Maass W: State-dependent computations:

spatiotemporal processing in cortical networks. Nat. Rev. Neurosci 2009,

10:113-125.

2. Hebb DO: The organization of behaviour. New York: Wiley; 1949.

3. Fujisawa S, Amarasingham A, Harrison MT, Buzsáki G: Behavior-dependent short-term assembly dynamics in the medial prefrontal cortex. Nat. Neurosci 2008, 11(7):823-833.

4. Mante V, Sussillo D, Shenoy KV, Newsome WT: Context-dependent computation by recurrent dynamics in prefrontal cortex. Nature 2013, 503(7474):78-84

5. Tetzlaff C, Kolodziejski C, Timme M, Tsodyks M, Wörgötter F: Synaptic scaling enables dynamically distinct short- and long-term memory formation. PLoS Comput Biol 2013, 9(10):e10003307.

6. Sussillo D, Abbott LF: Generating coherent patterns of activity from chaotic neural networks. Neuron 2009, 63(4):544-557.

doi:10.1186/1471-2202-15-S1-P10

Cite this article as: Tetzlaff et al:: The association between cell

assemblies and transient dynamics. BMC Neuroscience 2014 15(Suppl 1): P10.

\section{Submit your next manuscript to BioMed Central} and take full advantage of:

- Convenient online submission

- Thorough peer review

- No space constraints or color figure charges

- Immediate publication on acceptance

- Inclusion in PubMed, CAS, Scopus and Google Scholar

- Research which is freely available for redistribution

Submit your manuscript at www.biomedcentral.com/submit 